\title{
ON THE CORROSION OF LOCOMOTIVE BOILERS, AND THE MEANS OF PREVENTION.
}

\author{
By Mr. WILLIAM KIRTLEY, of Derby.
}

From the reports of accidents with Steam Boilers in this country during the last year 1865 , it appears that during that period 55 steam boilers have exploded, causing the deaths of about 56 persons and injury to a much greater number. Amongst these explosions there have been on the railways of the United Kingdom out of 7000 locomotives 11 boilers exploded, causing loss of life and injury in each case, and in addition serious destruction of property. Each of these explosions must have been occasioned either by defects of construction or material, or else by negligent supervision. It is intended in the present paper to consider only the subject of highpressure boilers, such as those of locomotives; and as in the large majority of exploded locomotive boilers it has been found that the explosion has arisen from the plates of the boiler having become weakened by corrosion at particular places, it is the writer's object to describe the nature and extent of this corrosion, and to endeavour to show the causes of its occurrence, together with the means of prevention.

In the present ordinary construction of locomotive boilers with lap joints, as shown in Figs. 7 and 8, Plates 13 and 14, the wear by corrosion of the plates is found principally round the smokebox end of the boiler barrel, in the interior, opposite to the edge of the outside angle iron, as shown at $\mathrm{AA}$ in Figs: 1, 2, and 3, Plate 12, where an annular groove is found to be eaten out of the plates by corrosion. This grooving extends sometimes so deep into the plate that only a thin shell of metal is left on the outside at the bottom of the groove, as shown in Fig. 3, which is a full size section of an actual case of the grooving; and the corrosion takes place so rapidly in many cases that the plates require renewal after only a few years' 
work. A similar grooving also takes place along the edge of the inside lap at the longitudinal joints, as at $\mathrm{D}$ and $\mathbf{E}$ in Fig. 6, and also at the transverse circular joints, as at BB in Figs. 4 and 5 ; but in the latter case the grooving does not occur so frequently nor is the extent of corrosion so great as at the smokebox end and at the longitudinal joints, as seen in the specimens exhibited of corroded plates from the different situations.

It has to be remarked first that this grooving is only found below the water line, showing that it must be due to the chemical action of the water on the plates; and the special point to be enquired into is the cause of this action being so remarkably concentrated at the particular lines where the grooving takes place. It will be seen from the specimens shown, which are taken from locomotive boilers that have been at work for various periods of from three years to as much as nineteen years, that some corrosion also takes place over the general surface of the plates; but this is very limited in extent compared to the grooving at the seams, and it occurs very irregularly, being apparently influenced by some irregularities in the structure of the plates, causing them to be pitted irregularly by the corrosion.

In the ordinary construction of locomotive boilers with lap joints, as shown in Figs. 7 and 8, Plates 13 and 14, the barrel of the boiler is constructed of three rings, each ring formed by two plates of 7-16ths inch thickness, rivetted with lap joints $\mathrm{FF}$ and $\mathrm{HH}$. The general amount of lap is $2 \frac{1}{4}$ inches for single-rivetted and $3 \frac{1}{2}$ inches for double-rivetted joints. The smokebox and firebox are each united to the barrel of the boiler by an angle iron KK, Fig. 8 , 3 inches or $3 \frac{1}{2}$ inches wide, welded into a ring. General experience has shown that after five or six years' wear of these boilers the grooving action that has been described is developed at the joints and at the edge of the angle-iron rings.

Now the longitrdinal strain upon the joints of boilers constructed in this manner tends to spring and bend the plates at the joints, when under pressure, into the form shown exaggerated in Fig. 9, in consequence of the plates not being originally in the line of strain, 
as shown by the dotted line SS in Fig. 8, which it will be seen runs along the outer face of one plate and the inner face of the next. Also in the longitudinal joints of the barrel, shown at FF in Fig. 7, a similar mechanical action takes place, the strain acting in the true circle shown by the dotted line SS, springing and bending the plates at the edge of the joints, as shown at GG, each time that the boiler is under pressure. The continued alternation of expansion and contraction in the boiler canses the scale that is deposited upon the plates from the water to be continually broken off at the edge of the joints by the mechanical action of this springing and bending of the plates at the lines of the joints; and the plates are thereby laid bare at those parts and kept continually exposed to the corroding action of the water, instead of being protected from the action of the water by the deposited scale remaining attached to them.

Though the corrosion produced by the water is slow in action and but slight in effect on the rest of the boiler plates, which are protected by some deposit of incrustation remaining almost constantly upon them, it becomes very serious on an exposed raw surface of iron; and this action is particularly severe in the case of locomative boilers, in consequence of the total quantity of water evaporated in a locomotive boiler being much greater in proportion to the surface of the plates than in stationary boilers. The particulars are given in the accompanying Table of the total work done and water evaporated during the time they were running, by the several locomotives of which specimens are now shown from the boilers; and from these particulars 10 million gallons of water may be taken as having been evaporated in a locomotive boiler during the five to eight years in which the plates have become corroded through. As this is nearly double the quantity evaporated in the same time by an ordinary stationary boiler having three times the surface of boiler plate exposed to the action of the water, the total work of the locomotive boilers may be considered as amounting to six times the evaporation per square inch of plate in the same time, and the total length of working as equivalent consequently to from thirty to fifty years' working of a stationary boiler. 
Particulars of Locomotives

from which Specimens of Corroded Plates were taken.

\begin{tabular}{|c|c|c|c|}
\hline $\begin{array}{c}\text { Number } \\
\text { of } \\
\text { Engine. }\end{array}$ & $\begin{array}{c}\text { Years } \\
\text { of } \\
\text { Working. }\end{array}$ & Miles run. & $\begin{array}{c}\text { Water consumed. } \\
\text { Gallons. }\end{array}$ \\
\hline 99 & 3 & 83,349 & $1,462,774$ \\
121 & $11 \frac{3}{4}$ & 334,711 & $5,874,178$ \\
123 & 12 & 290,380 & $5,096,169$ \\
141 & $8 \frac{1}{4}$ & 268,679 & $4,715,316$ \\
162 & $8 \frac{3}{4}$ & 255,042 & $4,475,987$ \\
187 & $8 \frac{3}{2}$ & 229,099 & $8,041,374$ \\
$235 *$ & 14 & 315,227 & $11,064,467$ \\
250 & $14 \frac{3}{4}$ & 316,391 & $11,105,324$ \\
255 & 14 & 293,559 & $10,293,920$ \\
274 & $13 \frac{1}{2}$ & 303,249 & $10,644,039$ \\
306 & $11 \frac{1}{4}$ & 229,162 & $8,043,587$ \\
$306 \dagger$ & $6 \frac{1}{4}$ & 142,808 & $5,012,560$ \\
369 & $10 \frac{1}{2}$ & 246,956 & $8,668,155$ \\
375 & $3 \frac{1}{4}$ & 67,072 & $2,354,227$ \\
388 & $8 \frac{1}{4}$ & 180,985 & $6,352,573$ \\
410 & $6 \frac{3}{4}$ & 158,801 & $5,573,915$ \\
422 & $8 \frac{1}{2}$ & 231,035 & $8,109,328$ \\
658 & $18 \frac{3}{4}$ & 249,672 & $4,381,743$ \\
\hline
\end{tabular}

* Flanged tabe plate. † After renewal with thick-edge plates.

It must further be noticed that the pressure under which the locomotive boilers are worked is much higher than in the case of stationary boilers, and the injurious action caused by the springing of the plates at the joints is therefore proportionately increased; and taking the pressures at $35 \mathrm{lbs}$. per inch for the stationary boiler and $140 \mathrm{lbs}$. for the locomotive, this makes the action four times greater in the locomotive boiler from this cause, taking the increase to be only at the same rate as the increase in pressure. Hence as the action is six times greater from the previous cause, a total is given of twenty-four times as great an extent of injurious action in the locomotive boiler as in the stationary boiler in the same length of time. As an illustration of the effects of increased pressure in increasing the corroding action, it may be mentioned that this grooving of the plates has been found to be materially increased in 
amount since the working pressure of locomotives has been increased from $100 \mathrm{lbs}$. up to the present $140 \mathrm{lbs}$. per inch.

In some of the older classes of locomotive engines the writer has found that there is an increased local action of serious amount caused in the boilers by the rigid points of attachment to the boiler barrel, such as frame stays, brackets, $\&$ c., which offer special points of resistance to the expansion of the boiler when under pressure. A specimen of this grooving, taken from No. 187 engine in the preceding Table, is shown at CC in Figs. 4 and 5, Plate 12, caused by the rigid attachment of the spectacle-bracket $\mathrm{M}$ to the boiler barrel. The result is made worse when the firebox is rigidly -fixed to the frames, or not allowed full freedom for expansion by the provision of a sliding bracket; as a great additional strain is thereby thrown on the tube plate, springing the angle irons round the ends of the boiler. The expansion of a $10 \mathrm{ft} .6$ ins. or $11 \mathrm{ft}$. boiler barrel being about 3.16 ths inch at a pressure of 140 lbs. per inch, an attachment to the frame at any other place besides the fixing of the cylinders and tube plate at the front end must subject the boiler to a bending strain at the points of attachment, causing a risk of corrosion at these points. In the Midland Railway engines all the other attachments except the smokebox angle iron are now removed, including that of the motion plate which carries the inner ends of the slide bars; and the boiler is allowed in expanding to slide freely throughout upon the frames.

In the longitudinal joints of the boiler the grooving from corrosion is generally found to be more marked when the inside edge of the lap faces upwards, as at $\mathrm{E}$ in Fig. 6, than when it is turned downwards, as at D. In the former case it may be considered that the deposit will collect upon the projecting ledge in larger quantities, forming a thickness of deposit sufficient to be detached bodily by the springing of the plate under pressure; and it will consequently leave the bare plate more frequently and extensively exposed to the direct action of the water, than when the edge of the plate faces downwards, as at $D$, because in the latter case the thinner film of deposit will not be so readily and frequently detached from the 
plate by the same action. It must be borne in mind that the earthy deposit itself, being chemically neutral, cannot have any injurious action upon the plate; except in the case of a stationary boiler heated from an external flue, where undue heating and expansion of the plate are caused wherever its inner surface is separated from the water by any considerable thickness of nonconducting deposit.

In the preceding Table are given the particulars of seventeen locomotives on the Midland Railway, from which the specimens now exhibited of corroded plates were taken; showing the length of time of working and the mileage and consumption of water before the plates had become so defective as to require removal. The average result is $10 \frac{1}{4}$ years' working, 255,645 miles run, and $7,618,778$ gallons of water consumed by each engine.

In the case of the boilers constructed in the ordinary manner, as already described, the plates cut out show the grooving action of the corrosion below the water line, while they are comparatively clean above. In No. 235 engine the tube plate was flanged and rivetted inside the boiler barrel; and the result of working shows the advantage of this mode of construction over the ordinary angleiron joint, since the plates at the smokebox end are not grooved along the end of the flange, as they would have been with an external angle iron.

From the foregoing consideration of the subject it therefore appears that the special corrosion of the plates at the joints is to be attributed to the combined operation of chemical and mechanical causes, the chemical action of the water in the boiler being concentrated upon those particular parts in consequence of the mechanical action produced at those parts by the strain upon the plates. That the combination of these two causes is requisite for producing this effect is shown by the middle of the plates being free from it, where they are exposed to the chemical action alone, without the mechanical action; and further by the joints in the upper part of the boiler above the water line being also free from it, where exposed to the mechanical action alone, without the chemical action. The removal of one of these causes will therefore be 
sufficient; and in the locomotive boilers now to be described this object has been aimed at by removing the mechanical cause which produced the springing of the plates at the joints.

From the particulars already given of the corrosion which takes place in locomotive boilers, it appears that the greatest injury takes place at the smokebox end of the barrel, where there is not only a great and sudden change in the thickness and rigidity of the plates at the edge of the angle iron, as at $\mathrm{J}$ in Fig. 8, but also a leverage for the springing of the plate from the outer line of rivets, as at $\mathrm{L}$ in Fig. 9. The consequence is the bending of the plate at the point $J$, as in Fig. 9, each time of being under pressure of steam, owing to the outer line of rivets $L$ being entirely outside of the line of strain $\mathrm{S}$ of the boiler plates. There is also a great tendency to injury of the angle iron, by this action tending to split it between the rivet holes at the outer line of rivets $L$.

The present plan adopted on the Midland Railway is found to obviate the injury previously experienced from corrosion; and this is accomplished by the use of plates rolled with thickened edges, as shown in section in Fig. 19, Plate 17, and shown exaggerated in thickness in Figs. 10 and 11. The ordinary thicknoss of 7-16ths inch is preserved in the body of the plate, and the edges are thickened to 5-8ths inch, with a long gradual taper in the thickness from I to I, Fig. 19, about 4 inches length. The effect of this long taper is that, when the plate is flanged, as at $\mathrm{N}$, in order to do away with the angle iron, the taper ensures a gradual springing of the plate, distributed over all that length, instead of the sudden bending concentrated at one point, as at $J$ in Fig. 9.

A similar section of thick-edge plate is also used at the transverse circular joints, as shown in Figs. 10 and 11, causing a gradual springing of the plates over a considerable length when under pressure, as in Fig. 11, instead of the former sudden bending at one point, as in Fig. 9. There is also an increased strength gained by this mode of construction, as the increased thickness of the plates between the rivet holes compensates for the loss of section by the holes. 
The practical working of the thick-edge plates is shown by the specimen exhibited from No. 306 engine in the preceding Table. The original boiler of this engine, constructed in the ordinary manner, was removed after $11 \frac{1}{4}$ years' working, as the plates were much grooved and pitted; and a new boiler constructed with the thickedge plates was substituted, which has continued at work $6 \frac{1}{4}$ years to the beginning of the present year. It was then found that the plates were free from grooving, although they were badly pitted.

A consideration of the ordinary construction of locomotive boilers and their defects shows that their construction admits of important improvement in the barrel, by removing the injurious strains resulting from the employment of lap joints, which throw the plates out of the line of strain, and by making the barrel truly cylindrical and circular throughout. These objects are effected by welding the longitudinal joints of the three rings forming the boiler barrel, and making these rings all exactly the same diameter, uniting them to one another with flush butt joints. This plan is now carried ont upon the Midland Railway, as shown in Figs, 16, 17, and 18, and exaggerated in thickness in Fig. 12, Plate 15. The meeting ends of each ring are turned in a lathe, and united by covering strips $O O$, formed of welded flush rings, shrunk on over the joints and double-rivetted. Strengthening hoops P P are also shrunk on the centre of each of the plates, crossing the longitudinal welded joints, and are secured by a few rivets. These hoops and covering strips for the joints are carefully blocked before being shrunk on, and the whole of the rivet holes are drilled after the hoops are in their places.

These boilers are consequently truly cylindrical at all parts, and no strain to which they are subjected bas any tendency to change their circular form. The effect of the longitudinal strain upon the transverse circular joints, as in Fig. 13, is found to be altogether inappreciable in practice, because the covering rings $O O$ could not yield to it without contracting in circunference in the form of a double cone, Fig. 13; and on this account, together with their greater thickness, they offer a greatly increased resistance as compared with simple lap joints. All possible effect of the 
longitudinal strain might indeed be entirely got rid of, if desired, by the further addition of inside covering strips at the butt joints, as shown in Figs. 14 and 15. At present the circular plates of these welded boilers are in two semicircular segments for the circumference of the boiler, and therefore require two welds; but the writer thinks the barrel of the boiler would be improved if each length were made of one plate only, whereby only one longitudinal weld would be necessary.

A remarkable corroboration of the correctness of this mode of construction is given by the samples exhibited from No. 658 engine, the boiler of which was constructed with butt joints all flush throughout, the transverse joints being covered by external hoops and the longitudinal joints by internal strips. This boiler has been at work nearly 19 years, having been started in 1847 ; but the engine being of smaller size than those now used with trains has only been employed as a spare engine for some years past. The plates of the boiler, which are the original ones and have never been repaired at any part, are all good, and the grooving has not taken place at the butt joints, a little irregular pitting alone being visible on the inside of the plates. The boiler has now been eut up only on account of the engine being abandoned from the great length of time it has been worked. The remarkable contrast shown by the freedom of the butt joints in this boiler from the grooving so nniversal with the lap joints in the ordinary boilers appears only to admit of being accounted for by the difference of construction of the joints in the two cases. In another engine of the same class, which was last broken up, after attaining the maximum mileage of 343,000 miles, the boiler plates were very badly grooved at the angle-iron joint at the smokebox end, showing that this part of the boiler remained as defective as in the ordinary boilers, the construction being the same as regarded this joint; while the rest of the joints being butt joints were free from the grooving.

The flanging, bending, and welding of the thick-edge plates for forming the boiler barrel are performed by the aid of machines specially designed for the purpose, which are shown in Plates 18 to 24 . 
The Flanging Machine is shown in Figs. 20 to 22, Plates 18 and 19. It consists of a horizontal table $A$, on which the thick-edge plate, shown black, having been previously heated, is laid and secured by clamps, being pushed forwards against the adjustable stop $B$, Figs. 20 and 21 , so that the thick edge projects beyond the edge of the table to the required extent for forming the flange. The roller $\mathrm{C}$ is then brought down with a slow motion by the eccentrics $D$, as shown in Fig. 21, being firmly held by guides $\mathrm{E}$ at each end in the frame of the machine; and the edge of the plate is thus gradually bent down to form the flange. The table $\mathrm{A}$ is made to slide upon the bed $\mathrm{F}$ of the machine, and is set up by adjusting screws $G$ to the required amount of clearance from the bending roller $\mathrm{C}$, according to the thickness of the plate to be flanged. The front edge of the table is faced with a separate wrought iron or cast iron edge-piece I, which can be removed and changed for another having a different curve for the edge, according to the curve that is desired in the neck of the flange. The holding-down bar $\mathrm{H}$ is screwed down tight apon the plate, immediately behind the edge of the table, so as to hold the plate down flat on the table while the flange is being bent by the roller. The working speed of this machine is 7 double strokes per minute.

The Bending Machine, for bending the thick-edge plates into the semicircle to form the boiler barrel, is shown in Figs. 23 and 24, Plates 20 and 21. It consists of three horizontal rollers, of which the two lower ones $\mathrm{AA}$ are carried in fixed bearings at each end in the frame of the machine; while the third roller $B$ slides vertically in the frame, and is lowered by the screws $\mathrm{CC}$ at each time of passing the plate through the rolls, to give the required degree of curvature to the plate. The screws CC were at first worked by hand, but are now driven by gearing from the main shaft. As the thickness of the body of the plate is only 7-16ths inch, while the thickness of the edges is 5-8ths inch, a liner plate 3-16ths inch thick is laid over the body of the boiler plate in the bending process, in order to make up the same thickness of 5-8ths inch throughout for passing through the rolls; and the liner plate is afterwards flattened again ready for subsequent use. At one end of each of the lower rollers $A A$ is a 
groove $\mathbf{D}$ to receive the flange of the plate; this groove is shown enlarged in Fig. 26, and is formed by a glut-piece or ring $\mathrm{E}$, screwed upon the roller spindle $F$ and tightened by a set screw $G$, by means of which the width of the groove can be increased or diminished according to the thickness of the flange of the plate. A corresponding groove is provided at the opposite end of the upper roller $B$, to allow of bending plates with the flange inside instead of outside. In order to obtain a sufficient hold upon the plate to pass it through the rolls, the surfaces of all the rollers are fluted longitudinally with shallow flutes at $1 \frac{1}{4}$ inch piteh, as shown in Fig. 26, and enlarged to half full size in the section, Fig. 25. The lower rollers only are driven by gearing, the upper roller being merely a pressing roller for giving the required curvature to the plates, and weighing about 25 cwts. The working speed of the rollers is 3 revolutions per minute, or about 12 feet per minute speed of surface.

The two semicircular plates are then welded together into a single ring to form one length of the boiler barrel. The edges to be welded are first heated in the fire at A, Fig. 29, and upset sufficiently to give the required thickness of metal for forming the scarf weld. A welding heat is then taken on a short length of the joint of the plates, and the plates $B$ are welded together along the joint upon the Welding Anvil, shown in Figs. 28 and 29, Plate 22. The anvil face $\mathrm{C}$ is shaped to the internal diameter of the boiler barrel, and is separate from the pedestal $\mathrm{D}$ of the anvil, so that it can be exchanged for other sizes of face, according to the diameter of the boiler. During the heating and welding, the plates $\mathrm{B}$ are held in the circular frame $\mathrm{E}$, in which they are securely clamped; and the frame $\mathbf{E}$ being slung from a crane, the plates are readily handled. The two ends of the joint are first tacked together by welding, to secure the correct diameter of barrel, and the joint is then welded in short lengths from the centre towards each end.

The rings of the boiler barrel when welded up are blocked, to test them by stretching and bring them to the diameter of the boiler. For this purpose the rings are first heated in the Blocking Furnace shown in Figs. 30 and 31, Plate 23, having the firegrate $\mathbf{A}$ under the centre, with six chimney flues $\mathrm{CC}$ round the 
circumference. The ring $B$ to be heated is put in from the top, and placed on end, with the heat from the fire passing up through the inside of the ring and then down all round the outside to the flues, so as to give a uniform heat to the ring.

The ring is then put on the Blocking Press, shown in Figs. 32 and 33, Plate 24; which is an ordinary hydraulic wheel-tyre blocking press, worked by a centre cone $D$ forcing out the blocking segments EE. These blocking segments are carried up for the purpose and strengthened by brackets, as shown in the drawing. One half of the height of the ring $B$ is blocked at once; and the ring is then turned over for blocking the other half.

The welded joints of these boilers have been tested by a series of experiments upon the tensile strength of strips of plate cut out across the weld, which were taken from several boilers from the opening cut out for the steam dome R, Fig. 16. Three sets of strips were tested, of $1,1 \frac{3}{8}$, and $1 \frac{1}{2}$ inch width respectively, and each $7 \frac{1}{2}$ inches length, cut out of the plate transversely to the weld, which was in the middle of each piece. The following was found to be the average breaking strength per square inch of these strips:-

Experiments to test strength of Welded Joints.

\begin{tabular}{|c|c|c|c|c|c|c|}
\hline \multirow{2}{*}{$\begin{array}{l}\text { Width } \\
\text { of } \\
\text { strips. }\end{array}$} & \multirow{2}{*}{$\begin{array}{c}\text { No. of } \\
\text { Strips } \\
\text { tested. }\end{array}$} & \multirow{2}{*}{$\begin{array}{c}\text { Broke } \\
\text { in } \\
\text { weld. }\end{array}$} & \multirow{2}{*}{$\begin{array}{l}\text { Broke } \\
\text { in } \\
\text { Solid. }\end{array}$} & \multicolumn{3}{|c|}{ Breaking Strength per square inch. } \\
\hline & & & & Least. & Greatest. & Average. \\
\hline $\begin{array}{l}\text { Inch. } \\
1\end{array}$ & 15 & 8 & 7 & $\begin{array}{l}\text { Tons. } \\
16.5\end{array}$ & $\begin{array}{l}\text { Tons. } \\
23.8\end{array}$ & $\begin{array}{l}\text { Tons. } \\
20 \cdot 2\end{array}$ \\
\hline $1 \frac{3}{8}$ & 4 & 2 & 2 & $19 \cdot 6$ & $22 \cdot 2$ & $21 \cdot 0$ \\
\hline $1 \frac{1}{2}$ & 4 & 1 & 3 & $18 \cdot 1$ & $23 \cdot 5$ & $21 \cdot 7$ \\
\hline Total & 23 & 11 & 12 & $16 \cdot 5$ & $23 \cdot 8$ & $20 \cdot 6$ \\
\hline Also & \multicolumn{3}{|c|}{$\left.\begin{array}{l}11 \text { Strips of the same } \\
\text { plates unwelded }\end{array}\right\}$} & $20 \cdot 7$ & $25 \cdot 8$ & $23 \cdot 6$ \\
\hline
\end{tabular}

From these results it appears that more than half of the strips broke in the solid and not at the weld, and the average breaking strength 
of the 23 welded plates was within 1-8th of the full strength of the 11 unwelded plates; while the worst pieces, including some cases of as extremely defective weld as are at all likely to occur in practice, had more than two thirds of the full strength of the unwelded plates.

In reference to the cost of construction of the welded boilers in comparison with the ordinary class of lap-jointed single-rivetted boilers with angle-iron ends, it has to be noted that there is an increase of weight of $1 \frac{1}{4}$ ton in the new boilers, the weight of the $11 \mathrm{ft}$. boilers, $3 \mathrm{ft}$. 11 ins. diameter, being $7 \frac{3}{4}$ tons as compared with $6 \frac{1}{2}$ tons in the old class of boilers of the same dimensions. This increase arises from the thick-edge plates, and from the hoops and joint strips, which weigh about $2 \frac{1}{4} \mathrm{cwts}$. each; and the joints, instead of being single-rivetted, are double-rivetted on each side of the joint, making four rows of rivets.

The total cost for labour and material is $£ 465$ in the new boiler, as compared with $£ 415$ in the old class, being an increase of $£ 50$ in each new boiler. The labour alone in the new boiler is $£ 65$ as compared with $£ 55$ in the old class, being $£ 10$ increase in the new boiler. In these costs however the whole labour is taken as hand work in both cases; but from the present experience it appears that the item of labour in flanging and bending is now reduced more than one half by the use of the flanging and bending machines that have been described. In the construction of the new boilers the cost of welding, as regards labour, has averaged $7 s$. per lineal foot of joint. The cost of the welding tackle, as shown in the drawings, has been $£ 25$ to $£ 30$.

There have been nineteen of these welded boilers in constant use upon the Midland Railway for the last $6 \frac{1}{2}$ years, and the result has proved so thoroughly satisfactory that this construction has now been permanently adopted for the engines of this line. $U_{p}$ to the present time all these nineteen boilers have been examined once, and have been found in good condition; the mileage of each during the $6 \frac{1}{2}$ years that they have been running has been equal to about 175,000 miles, and each boiler has had one set of tubes worn out. 
As yet however they show no signs of grooving even at the flanged ends, where the greatest corrosion took place in the old construction with the angle-iron joints. Two of these boilers have been examined twice, and were also found to be in good condition at the second examination.

Mr. W. KIRTLEY exhibited a large number of specimens of corroded plates from locomotive boilers of the ordinary construction, together with specimens of the thick-edge plates, flanged and bent; and also the strips of welded plate that had been broken in testing the strength of the welded joints.

Mr. W. NAYLOR thought the importance of the subject brought forwards in the paper just read was sufficiently established by the fact which had been mentioned of there having been as many as eleven explosions of locomotive boilers during the last year, due mainly to the effects of corrosion. The increase of pressure that had taken place in locomotive boilers during the last thirty-five years, from $50 \mathrm{lbs}$. to as much as 160 lbs. per square inch, had no doubt much to do with the repeated explosions that still occurred; and though he believed the high pressure of $160 \mathrm{lbs}$. had been adopted for the sake of economy in the application of the steam, he doubted whether economy was really gained by it in practice, taking into consideration the greater wear and tear of the boiler and gearing; but even if that were the case he thought that safety should be the first consideration, and economy might then follow. At present it was clear from so large a number of explosions having occurred during the past year that safety was giving way to economy ; and he strongly recommended that the working pressure should be reduced from $160 \mathrm{lbs}$. to not more than $120 \mathrm{lbs}$. per square inch. 
The construction of boiler described in the paper appeared to him certainly a step in the right direction, by getting rid of the strains which caused the corrosion to produce such serious effects in ordinary locomotive boilers. The defects of the present construction of locomotive boilers with rivetted lap joints, and the danger of employing a high pressure of steam with such a construction, were rendered apparent even in the testing of the boilers by hydranlic pressure, before they were put to work. For in testing boilers of 50 inches diameter in the barrel and 60 inches across the firebox, with water pressure ap to 200 lbs. per square inch, the joints were found to appear sound up to about 150 or $160 \mathrm{lbs}$, but when the pressure was increased to $200 \mathrm{lbs}$. there were numerous leakages at the joints, showing that joints so made were not sound under so high a pressure. Taking the direct tensile strain upon the iron, if the plates were $\frac{1}{2}$ inch thick the tensile strain with a diameter of 60 inches and the pressure of 200 lbs. per square inch amounted to 12,000 lbs. or nearly $5 \frac{1}{2}$ tons per square inch on the section of the iron; and therefore at the longitudinal lap joints there was a force of $5 \frac{1}{2}$ tons per square inch acting at a leverage of $\frac{1}{2}$ inch to spring the joint open and bend the plates, while at lower pressures the strain upon the joints was proportionately less. Hence taking into account the continual variations of pressure to which locomotive boilers were subjected in working, he fully concurred in the view given in the paper, that it was the mechanical action of the strain upon the lap joints which produced the serious effects of corrosion that were observed. This was also confirmed by the experience of locomotive boilers made with butt joints instead of lap joints, as in the case mentioned in the paper of the boiler made by Messrs. Sharp Roberts and Co. in 1847 (No. 658), where there was no grooving at the butt joints; and he had lately examined a similar boiler made by Messrs. Slaughter, which showed no signs of grooving after twenty years' work. It was true these boilers had not been subjected to any excessive pressure, such as $160 \mathrm{lbs}$. per square inch; but the entire absence of furrows at the joints after that long period of working was nevertheless a satisfactory proof of the advantage of butt 
joints. The longitudinal tensile strain upon the plates forming the barrel of the boiler was not nearly so great as the lateral strain, for the area of the ends was much smaller in proportion to the circumference by which the strain was borne; but with the leverage afforded by the lap joints, this amount of strain was still sufficient to produce the serious grooving that was found at the transverse circular joints of the boiler barrel, and at the angle-iron joints at the smokebox and firebox ends.

The rivetting of the joints in boilers was also a source of weakness in the construction. For with the ordinary $\frac{7}{8}$ inch rivets placed at 2 inches apart centre to centre there was only 56 per cent. of the metal left at the rivetted joints as compared with the body of the plates. At the same time the plates were to a certain extent deteriorated by the strain put upon the iron in punching the rivet holes; and he had found by experiment that the strength was as much as 10 per cent. less after punching the holes, as compared with drilling them, when there would be no strain put upon the fibre of the iron in making the rivet holes. Altogether therefore the strength at the rivetted joints could not be taken as more than about 50 per cent. of that of the solid plates, and hence it was highly important that some other mode of uniting the plates should be adopted; and he thought the welding of the longitudinal joints, as described in the paper, was decidedly a good plan, and the specimens exhibited of the welded plates that had been tested showed that the welding had been very satisfactorily accomplished. Although this was the best mode of construction that had yet been adopted, it still involved the risk of the weld being unsound, to which all welding was exposed; and he believed there would be a still further improvement effected before long, by having the several lengths of the boiler barrel rolled each complete in a solid hoop, without any longitudinal joint, in the same way that tyres were already rolled out of a solid piece of metal without any weld.

He agreed with the statement made in the paper as to the corrosion being much more serious below the water line than above; but there were also certain places above the water line in locomotive boilers, where he had observed the effects of corrosion 
to be particularly marked, and these were along the top corner of the back plate of the firebox shell, and at the angle-iron joint round the base of the steam dome. In both of these places he had found a considerable grooving in several boilers that he had examined; and it would be remembered that in the case of a recent explosion of a locomotive boiler on the Metropolitan Railway it had been found that the steam dome had been blown off, which no doubt was due to corrosion having taken place round the base of the dome, the mechanical action of the bending of the plates under pressure being concentrated at that part in consequence of the hole cut out for the steam dome.

Mr. F. W. WEBB remarked that, in reference to the working pressure employed in locomotive boilers, the pressure in the locomotives on the London and North Western Railway was limited to $120 \mathrm{lbs}$. per square inch, and that had been the limit for many years past. The plan that had been long adopted on the same line for partially obviating the defects of the ordinary lap joints had been the telescopic form of boiler, in which the circumference of the successive plates was smaller towards the smokebox end of the barrel, each successive plate being put inside the preceding one, so that the strain was more nearly in the line of the plates, though not entirely so; and by this means the bending action upon the transverse circular lap joints was considerably reduced. This did not however make such a perfect job as the butt joints with outside cover plates, of which they had now had ten years' experience on the London and North Western Railway for the longitudinal joints. A great many of these boilers with butt joints had been examined, and there had not been any corrosion observed along the longitudinal joints, as the plates were not subjected to any material bending at those joints; but a considerable grooving had been found to take place at the transverse joints, opposite to the edge of the outside lap; and there was the usual deep grooving at the angle-iron joints at the smokebox and firebox ends, where the bending action still came into play.

The grooving which had been mentioned as taking place along: the top corner of the back plate in the firebox shell was not owing 
so much to corrosion, he thought, as to the severe bending strain thrown upon that part, whenever the firebox end of the boiler was not left perfectly free between the frames so as to allow for expansion and contraction. In the case of six engines that had been handed over to the London and North Western Railway from another line, the plates were observed to appear much corroded at this point, and became worn through after three years" longer working, and the wear could not be explained at the time; but in repairing the engines, the firebox end, which had previously been rigidly attached to the frames, was left free to slide, and after that there was no further difficulty from corrosion at this part of the boiler.

The Chairman enquired whether any trial had been made to ascertain what would be the extent of corrosion in a boiler that was not at work, leaving the boiler full of water for a length of time and using it in fact merely as a tank, and whether the corrosion would then occur at the same places where it was now found in the boilers at work.

Mr. F. W. Wrib.did not know of any experiment of that sort having ever been tried; but it was not likely that any grooving at the joints would take place when the boiler was not subjected to the mechanical action from the alternation of the pressure. In the locomotive boilers on the London and North Western Railway the present practice was to form each length of the barrel out of a single plate bent round into a complete circle, so as to have only a single longitudinal joint instead of two; and this joint was then turned to the upper side of the barrel, so as to be in the steam space above the water line, whereby they had now almost entirely got rid of the difficulty of corrosion along the longitudinal joint.

The corrosion over the general surface of the plates depended a good deal, he believed, upon whether the boiler was fitted with iron tubes or brass tubes, particularly where the water employed in the boiler had any acid properties. For in the case of locomotives running upon some parts of the Yorlsshire section of the London and North Western Railway where the water was of a very acid quality, he noticed that in boilers having iron tubes it was found 
the general surface of the plates was not injured, on examining them when the tubes were taken out after five or six years' work; but the corresponding boilers worlzing under the same circumstances with brass tubes were found to have the plates very badly pitted all over, which was no doubt owing to some galvanic action between the brass and iron.

The injurious effects of straining in locomotive boilers by alternate expansion and contraction were plainly shown in connection with the use of the injector for supplying the feed water to the boilers. The injector being originally placed at the side of the firebox, delivering the feed water in at that part, it was found that the constant straining of the outside firebox plate, from the continued changes of temperature owing to the intermittent stream of feed water supplied by the injector, caused the plate in a short time to become nearly cut through at the bottom close to the foundation ring of the firebox. This was partly due however to want of proper management on the part of the enginedriver in regulating the feed according to the rate of evaporation in the boiler, so that he was continually turning the injector on and off; but with proper care the injector could be so regulated as to deliver a constant stream of feed water into the boiler, in which case the firebox plate was kept at a more uniform temperature, and did not become injured by straining.

Mr. J. Fennie remarked that, with regard to the grooving which had been mentioned of the back plate of the firebox along the top corner above the water line, he had also noticed the same occurrence in locomotive boilers which he had examined; but he believed that in every case which he had seen the grooving at this part had been the result of bad workmanship originally. The plate had either been overheated at that place in the flanging, or had not been sufficiently sound to stand the flanging, or there had been some defect in the manufacture of the boiler which would account for the grooving. He thought therefore this was altogether a different case from the grooving round the angle-iron joint at the smokebox end, where there was no doubt that the corrosion took place whether the plate was really sound in material or not. 
In the testing of the strips of welded plate that were exhibited, the average breaking strain struck him as being much lower than might have been expected, considering that the thickness of metal at the weld was greater than in the body of the plate; and he had been surprised to find that so many of the strips gave way at the weld. He thought however that this might perhaps be attributed to the manner in which the strips were obtained for testing, being taken from the piece of plate cut out of the boiler across the weld to form the hole for the steam dome; and this piece of plate being bent to the circle of the boiler, it was possible that sufficient care might not have been exercised in flattening the strips before testing them, and the strength of the iron might have been injured in the straightening. He suggested that it would be well to try testing the strips in their original curved form, without flattening them; and he thought it would also be desirable to take strips of a greater width than only 1 inch, when a more satisfactory result would probably be arrived at.

Having seen the welded boilers described in the paper in all the stages of their manufacture, and having also seen them tested to a pressure as high as $200 \mathrm{lbs}$. per square inch, he had great pleasure in bearing testimony to the very capital job that was made by this mode of construction, and there was no mistake that they were first-rate boilers both in workmanship and strength; they were indeed the strongest locomotive boilers running at the present time. With regard to the proposed plan of making the rings of the boiler barrel each in a solid hoop without welding, he understood that some experiments had been already made for accomplishing this object; and he should be glad to know whether it was intended to roll the hoop in the same way that weldless tyres were rolled, or to draw it like a tube. There was not much probability he thought of the working pressure being reduced in locomotive boilers ; for the great aim now upon the railways was to obtain increased engine power for drawing the increased weight of the trains and for attaining a higher speed. For these purposes increased pressure of steam was required and stronger boilers, and the boiler described in the paper was an important step in that direction. 
Mr. W. NAYLOR observed that an important fact bearing upon the strength of locomotive boilers when under pressure of steam was that the tensile strength of the plates was greater at the temperature of the high pressure steam than when cold. Having had frequent occasion to test the strength of wrought iron plates and bars for the Great Indian Peninsula Railway, he had found that it was usual to wait till the iron was cold, under the impression that the test would otherwise not be a fuir one; and he had accordingly tried an experiment with a piece of best Yorkshire bar iron in order to ascertain the difference of strength when the iron was exposed to about the heat of a locomotive boiler. The bar was 2 inches by 1 inch, or 2 square inches section, and was cut into three lengths; and the two end pieces being tested cold broke at 51 tons tensile strain or $25 \frac{1}{2}$ tons per square inch. The centre piece was then heated red-hot, and was allowed to cool gradually until an alloy of lead and tin would only just melt upon it, showing that the temperature was about $350^{\circ}$ Fahr. or about the temperature of $120 \mathrm{lbs}$. steam. At this temperature the bar required 61 tons or $30 \frac{1}{2}$ tons per square inch to break it, showing a tensile strength 20 per cent. greater than when cold. It was also found that the heated bar did not stretch more than half as much as the cold bars before breaking.

Mr. W. S. LoNGRIDGE remarked that, in respect to the proposed plan which had been referred to of making the boiler barrel solid without any weld, he had been aiming at the accomplishment of this object for some time, and was more than ever confirmed in the idea by the information which had been given in the paper regarding the improved welded boilers and their advantages in freedom from corrosion as compared with the ordinary lap-jointed boilers. The object he had in view was only to extend to boiler plates the same plan of manufacture that he had already adopted in making weldless tyres, which had been found so successful that they were becoming more and more universally used; and in a few years he was satisfied that no tyres would be used which were made with a weld. He hoped in a short time to be able to make a weldless cylinder of boiler plate up to 4 feet diameter; and though the details of the mode of manufacture were not at present 
completely worked out, the intention was to build up a cylindrical coil, welded in the same way that guns were now constructed, from a double coil made of bars about $2 \frac{1}{2}$ inches square, having a 5 inch hole through the centre of the coil: this coil, after being forged and expanded in the usual way to 15 or 16 inches diameter of hole, to be bored and turned. The object of boring and turning was not only to ensure the soundness of the iron in the previous stages of manufacture, before the bloom was submitted to the final process of rolling, but also to allow of greater accuracy being obtained in completing the finished ring. This bloom of 16 inches inside diameter having then been subjected to a welding heat in the furnace would be taken to the rolling machine, and rolled out to 4 feet diameter. This process might be accomplished after a little experience as easily he thought for a boiler barrel as for a tyre; and though at first it was not intended to attempt rolling the hoops of a greater length than $3 \frac{1}{2}$ feet, he considered that when this was successfully effected it would only be a question of strength and size of machinery to roll an entire boiler barrel of 10 feet length. The experiments he was making were with iron; but had it not been for the prejudice at present met with against the use of Bessemer metal or other homogeneous metal for boilers, he would at once have adopted these for carrying out this system of boiler making, being satisfied that they would ultimately supersede iron for the purpose.

One point which had not been touched upon in the very interesting paper that had been read was the question of singlerivetted or double-rivetted joints ; and as he observed that in all the specimens of corroded plates which were exhibited the lap joints were single-rivetted, while the improved boilers with butt joints had the outside covering hoops double-rivetted, he enquired whether it was considered that the single-rivetting employed with the ordinary lap joints had anything to do with the grooving of the plates at the joints, and whether it was on that account that double-rivetting had been adopted in connection with the butt joints in the improved boilers. 
Mr. W. Kirtue replied that the double-rivetting of the butt joints in the improved welded boilers had been adopted only for the purpose of ensuring greater strength at the joints; and he did not think that the use of double-rivetting instead of single-rivetting would make any sensible difference in the extent of the grooving by the corrosion in the case of the ordinary lap-jointed boilers, as the injurious springing of the plate under pressure would be little affected.

With regard to the strips of welded plate that had been tested for trying the strength of the welded joints, the straightening of these before they were tested had been done with special care, in order that the strength might not be injured; and he thought the results might be taken as fairly representing the strength of the welds.

The Chairman moved a voto of thanks to Mr. Kirtley for his paper and the valuable specimens exhibited, which was passed.

The following paper, communicated through Mr. Walter May, was then read :- 
CORROSION OF LOCOMOTIVE BOILERS. Plate 12.

Diagrams showing Grooving caused by Corrosion in ordinary Boiter Barrels with Angle-Fon and Lap Joints. Groaving at Angte-Iran Joints at Streakebox ared Firebox ends. Fig.1. Plan of Irwide af Boiter Plaze at smokebox enet.
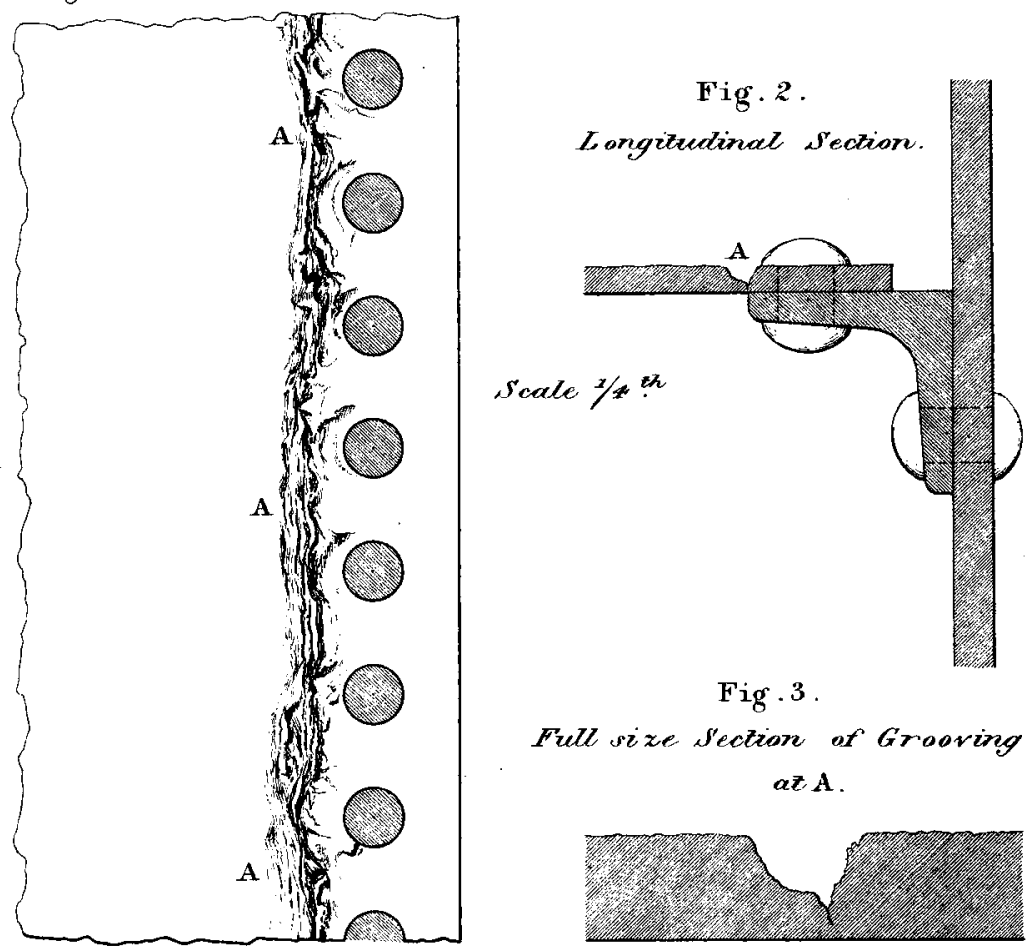

Fig. 4. Grooving at Trangverse Gircular Joints \&:

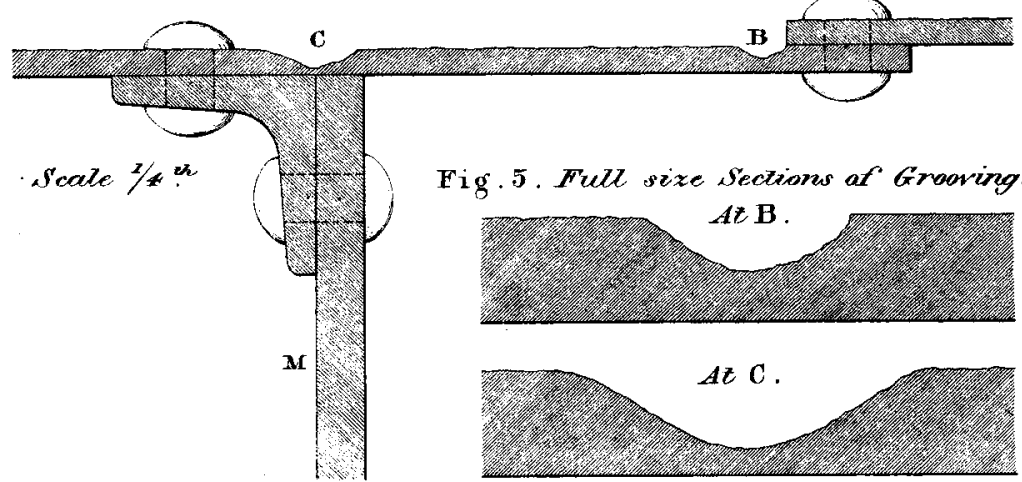

(Procedirgs Truz. M. E. 1866. Page 56.) 
CORROSION OF LOCOMOTIVE BOILERS. Plaze 13.

Diagrams showing Grooving caused by Corrosion in ordinary Boiler Barrels wizh Lap Joinzs.

Fig. 6. Grooving at Longizudinal Joints.

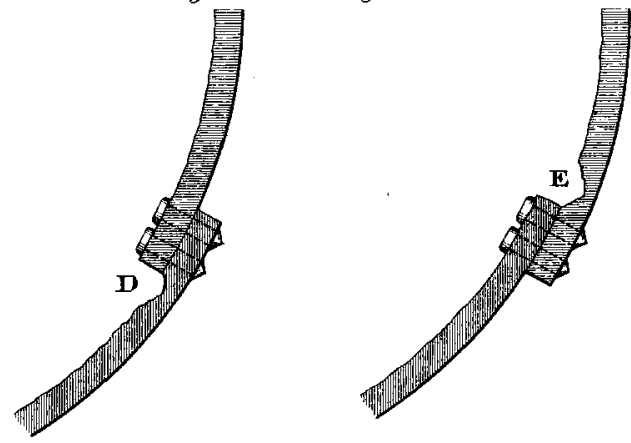

Fig.7. Transverse Section of Ordinary Boiter Barrel with Longitudinal Lap Soints.

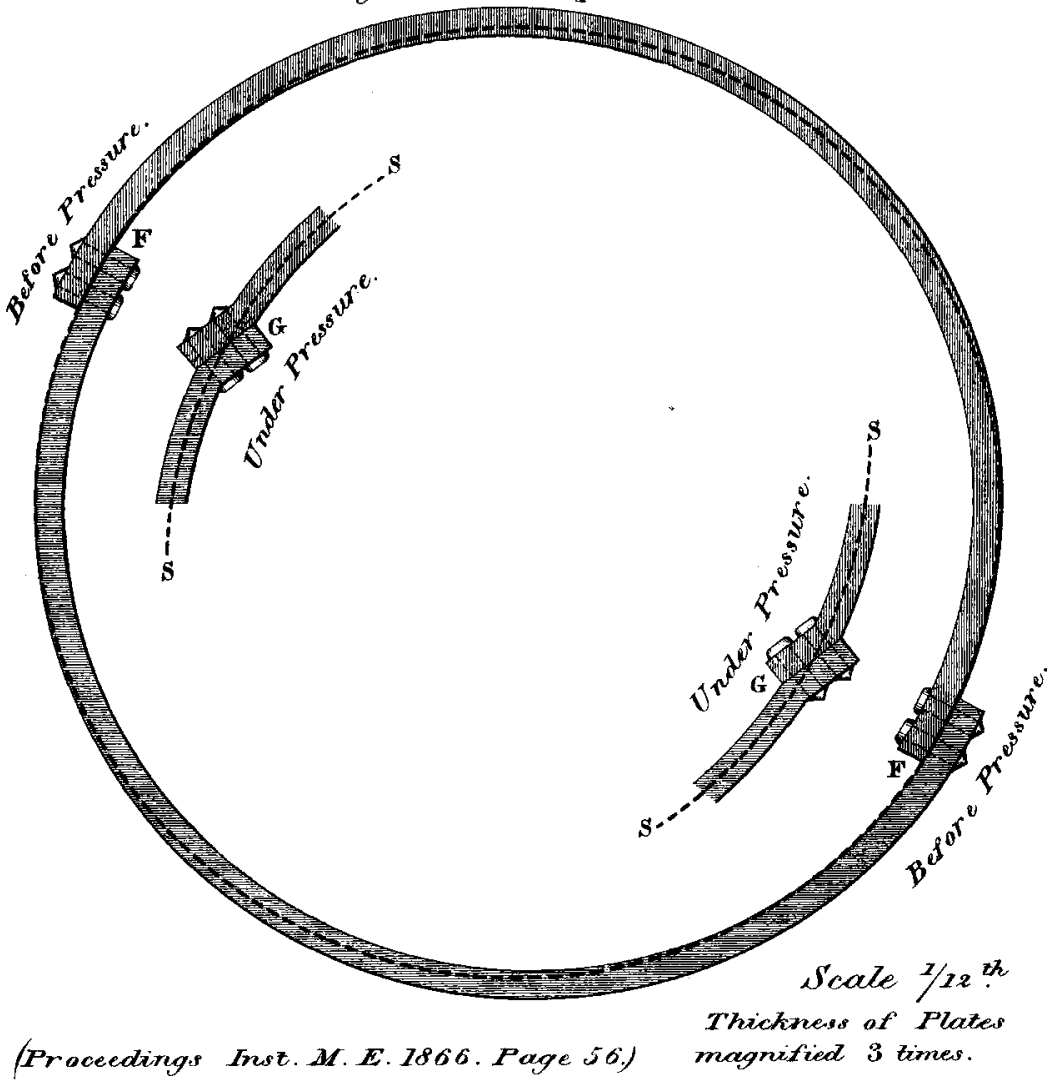


Diagrams showing tine of thongizudinat strain in Hoiter Barret, Zefore pressure and zender pressure.
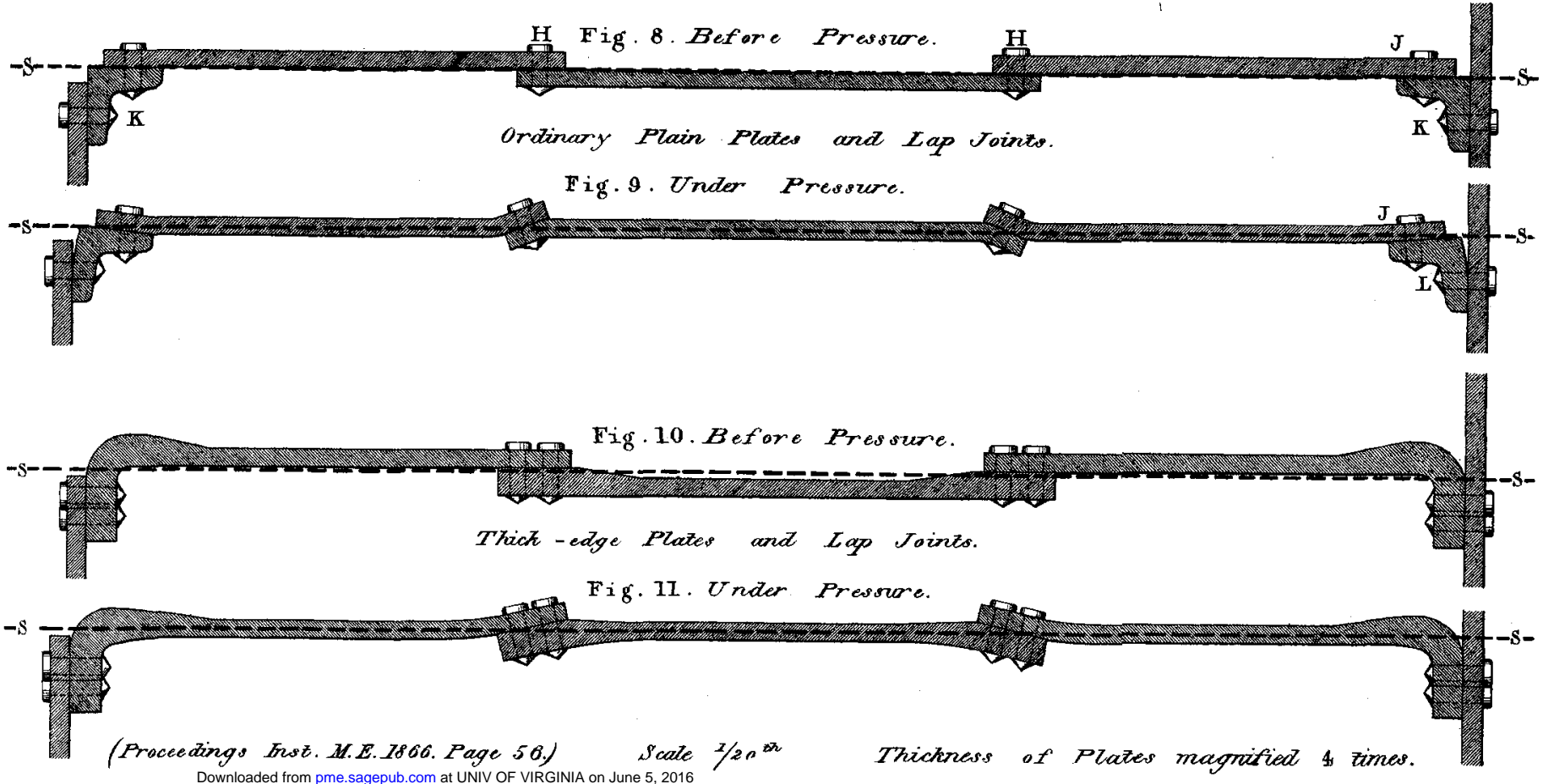
CORROSION OF LOCOMOTIVE BOILERS.

Plate 15.

Diagrams showing tine of Longitudinal Strain in Boiter Barrel, before pressure and water pressure.
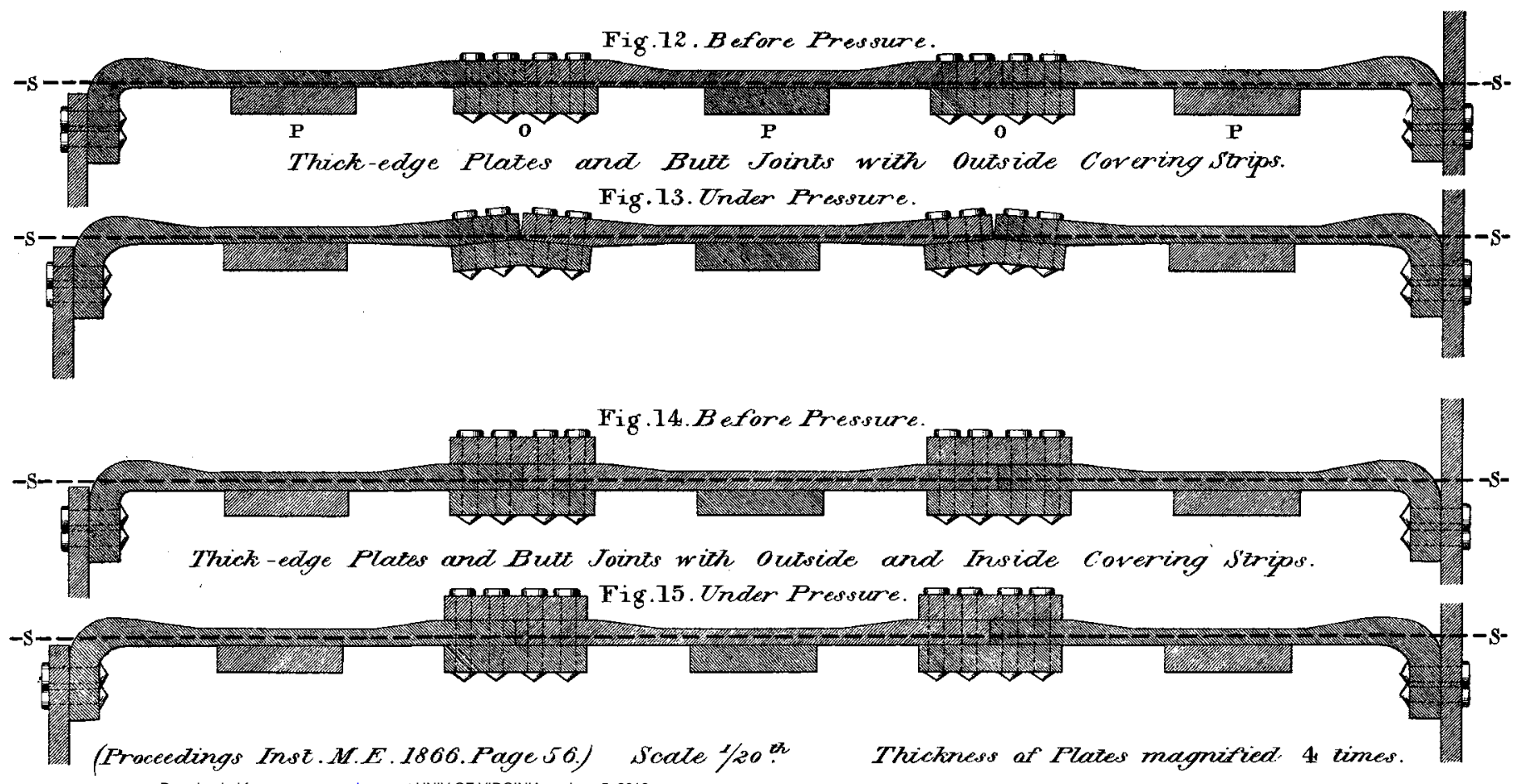
Downloaded from pme.sagepub.com at UNIV OF VIRGINIA on June 5, 2016 


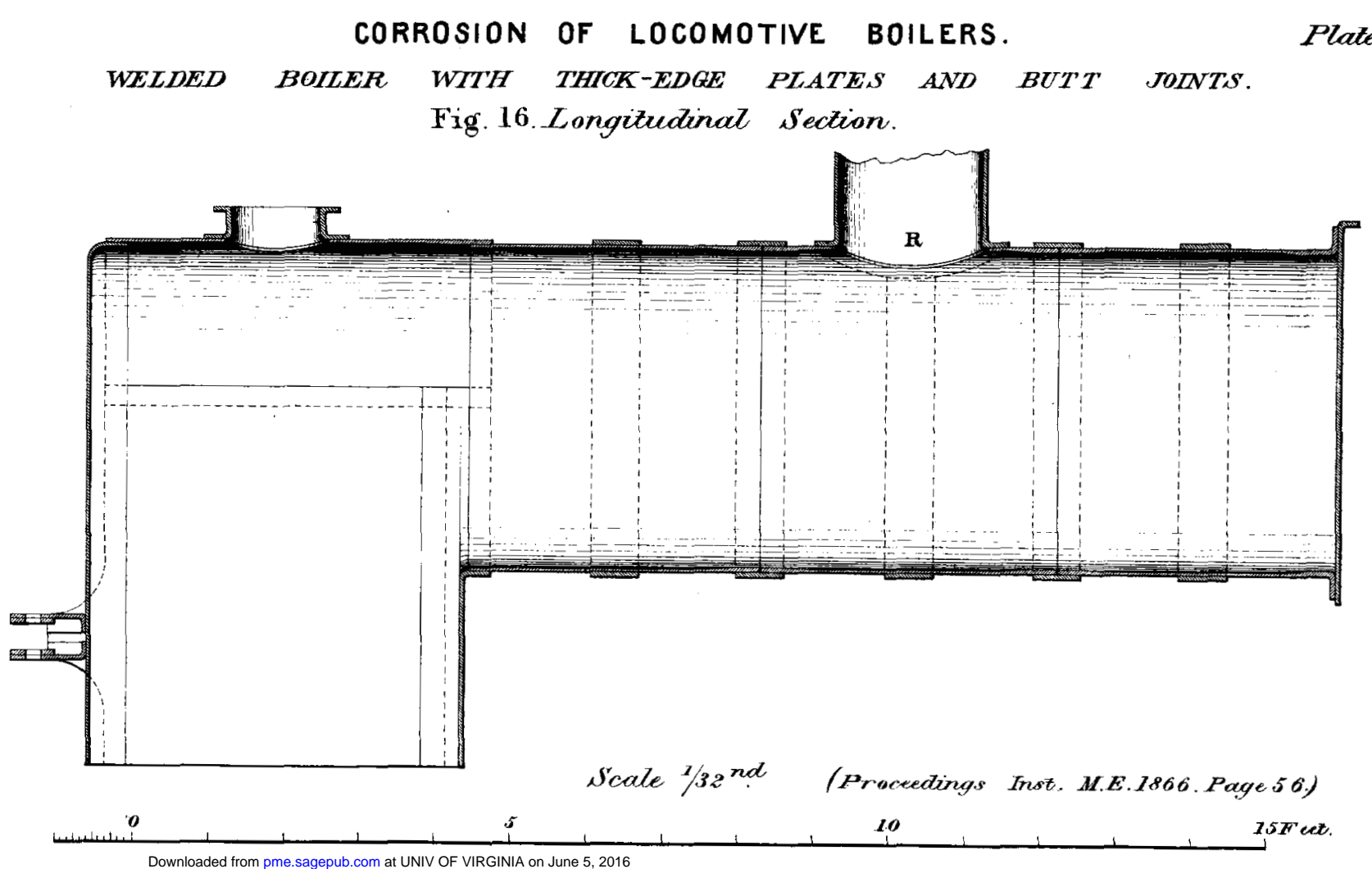

Downloaded from pme.sagepub.com at UNIV OF VIRGINIA on June 5, 2016 
CORROSION OF LOCOMOTIVE BOILERS.

Plate 17.

WELDED BOILER

WITH THICK-EDGE

PLATES

$A N D$

Fig.17. Sectional Plan. Scate $1 / 32$ nd

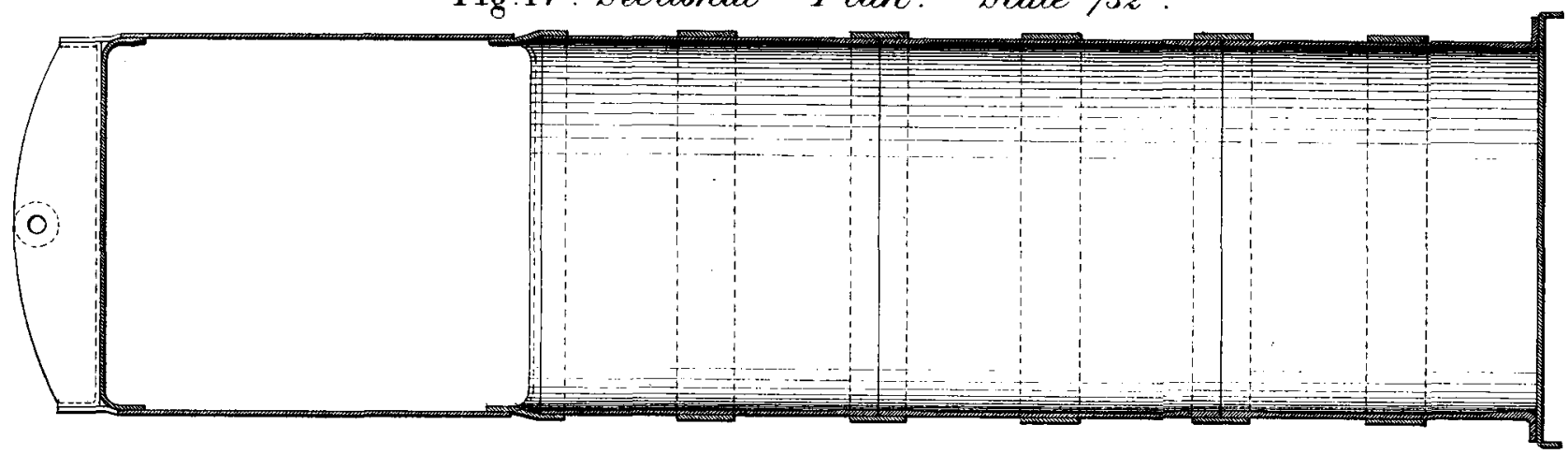

Fig.18. Entarged Section of Thick-edge Plates, showing Butt Joints in Boiter Barrel. Scale $7 / 8$. $\frac{\text { I }}{\frac{1}{1}}$

I

Fig.19. Entarged Section of Thick-edge Plates, show

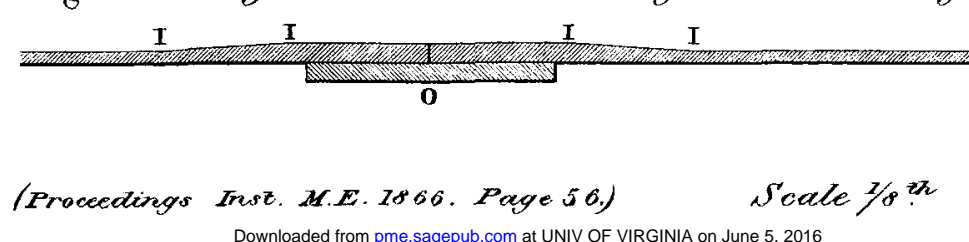
$\frac{\mathbf{I}}{\mathbf{P}} \frac{\mathrm{I}}{\mathbf{0}}$ 
CORROSION OF LOCOMOTIVE BOILERS. PlaZE 78.

FLANGING MACHINE.

Fig. 20. Transverse section.

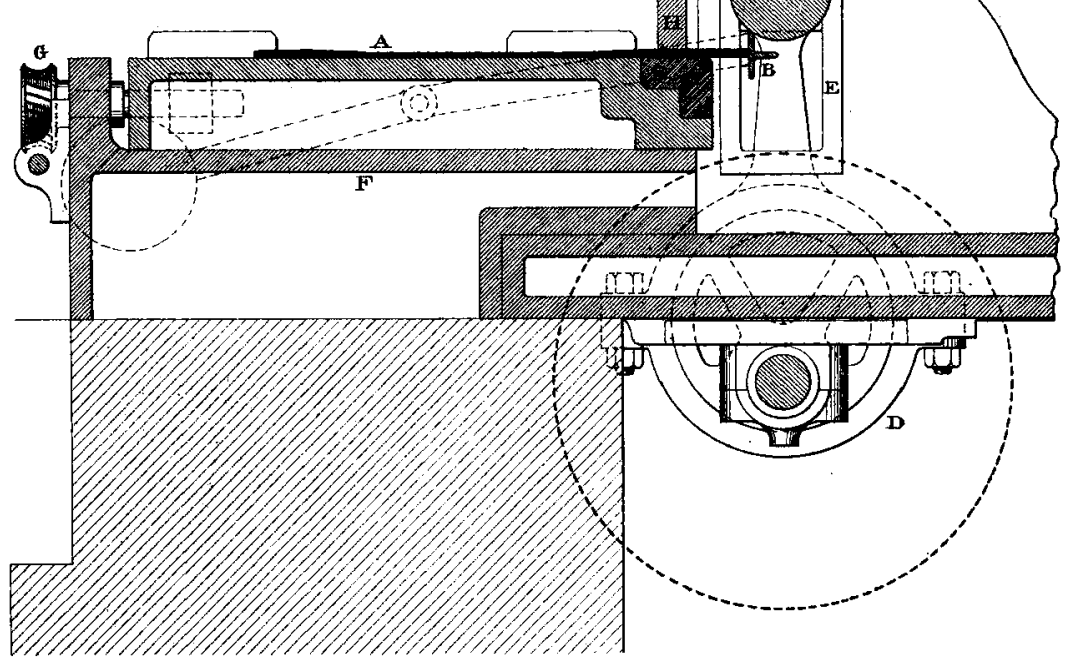

Fig. 21. Rolter descending.

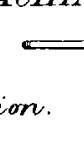


CORROSION OF LOCOMOTIVE BOILERS.

Plate 19.

FLANGING MACHTNE .

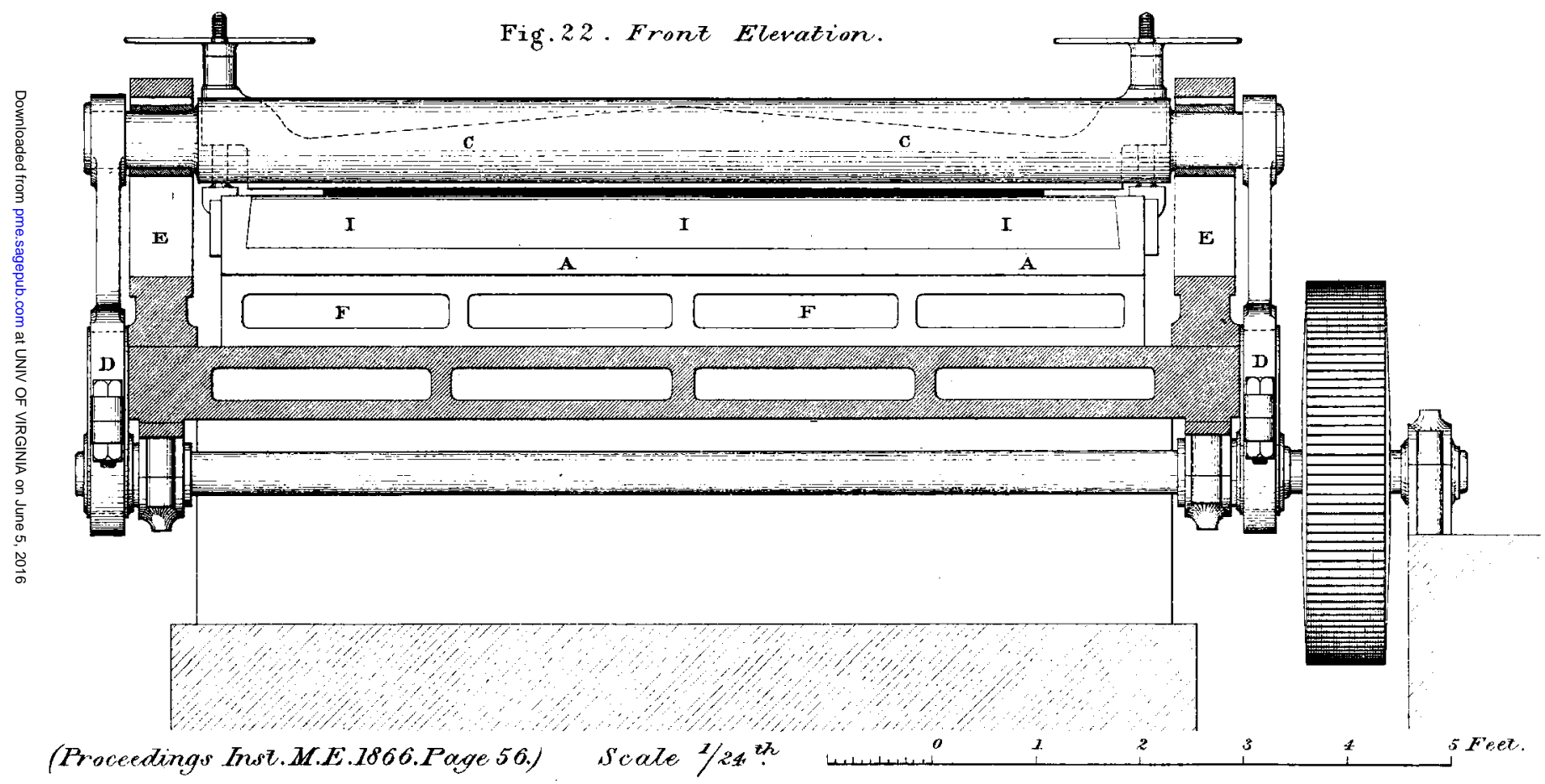




\section{CORROSION OF LOCOMOTIVE BOILERS.}

BENDING MACHINE.

Fig.23. Fronz ËZeration.

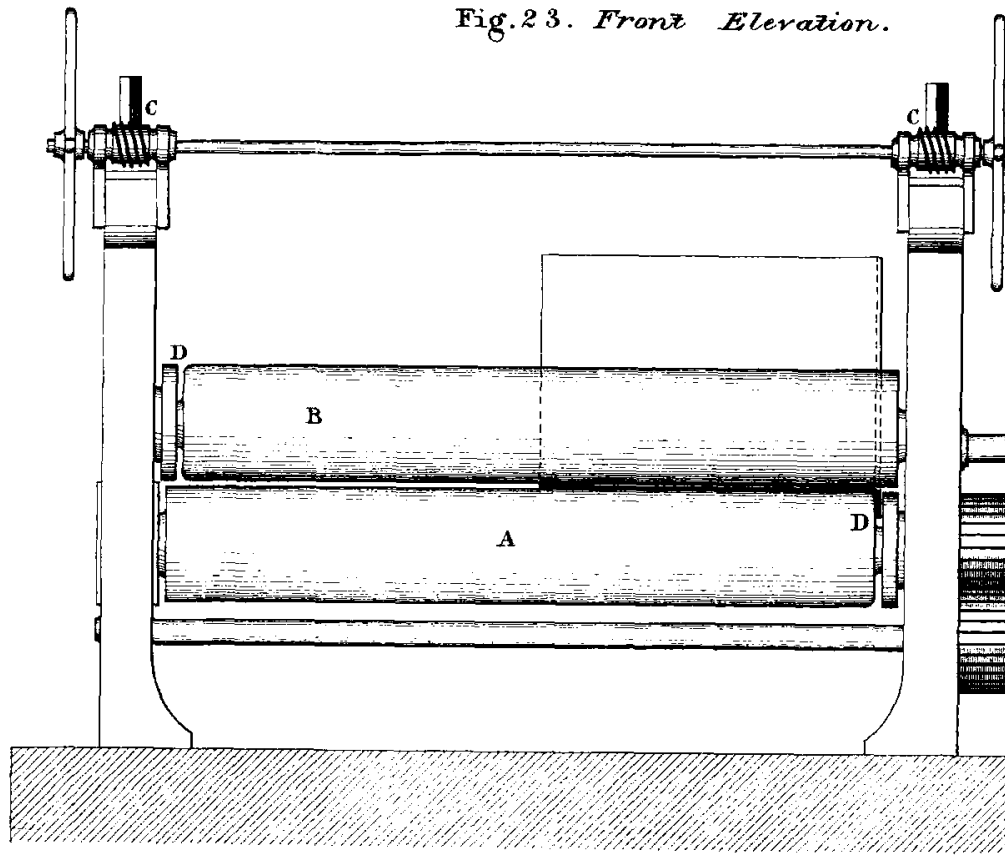

(Proceedings Inst.MT.E. 1866. Page 56.)

Downloaded from pme.sagepub.com at UNIV OF VIRGINIA on June 5, 2016

45


CORROSION OF LOCOMOTIVE BOILERS. BENDING MACHINE.

Fig.24. Transwerse Section.

Fig. 25.

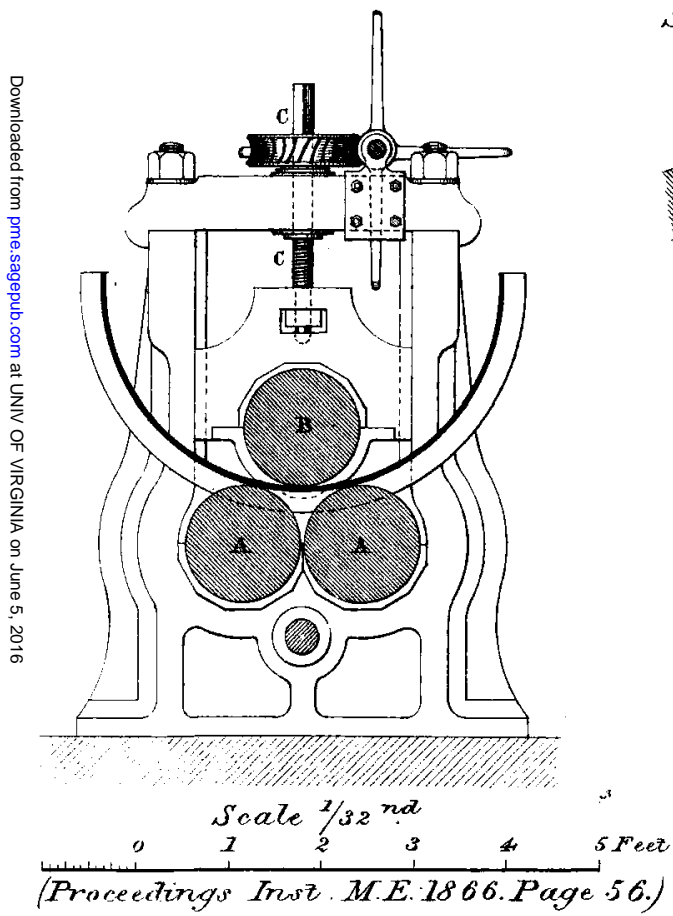

section of Fluted Surface of Rollo. scate half full size.

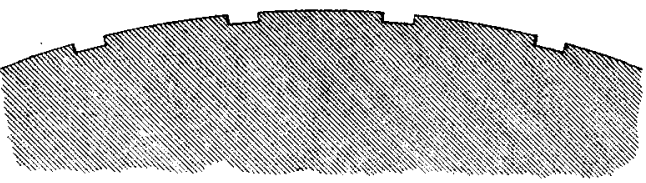

Fig.26. Section of Groove at end of Rolls to receive Flange of Plaze.

Fig.27. End Elevation.
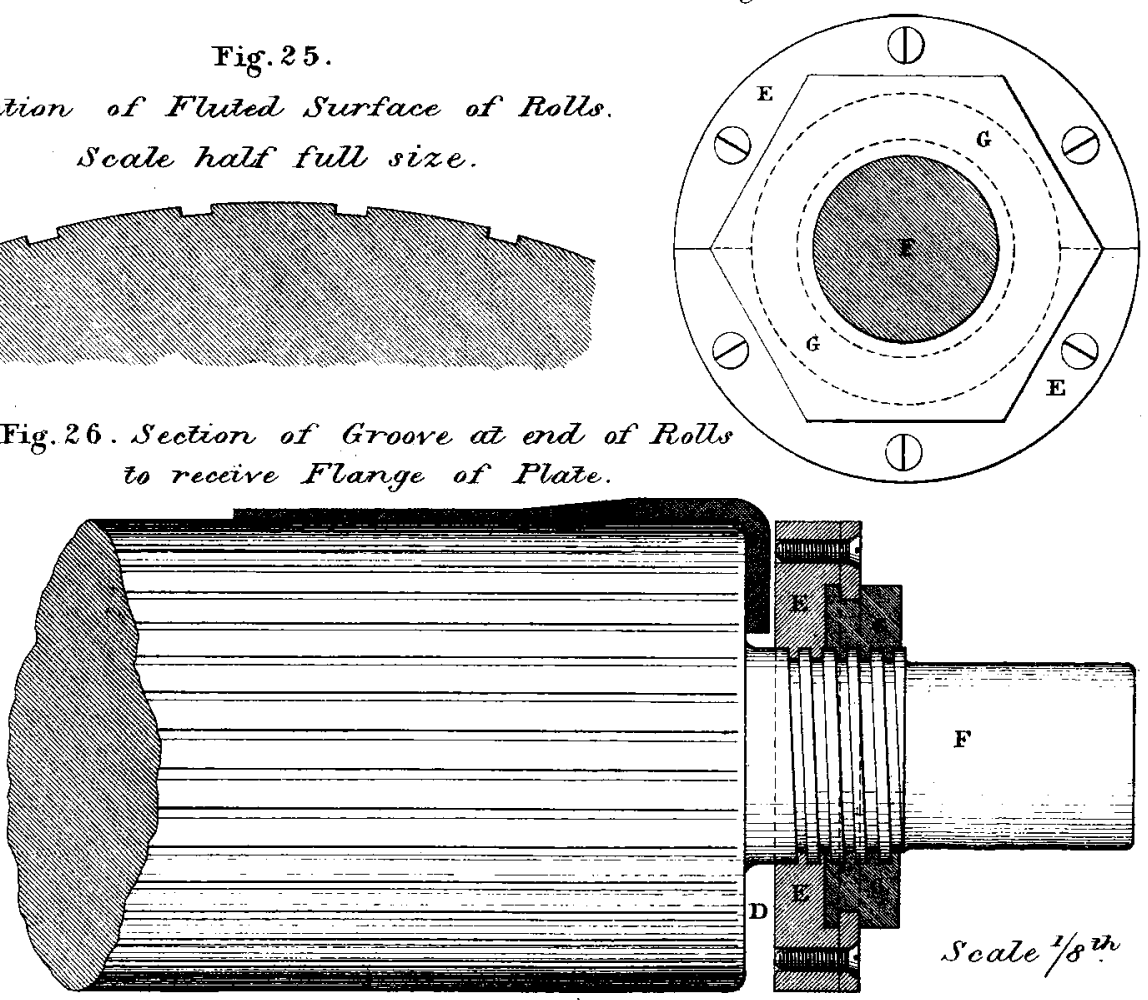


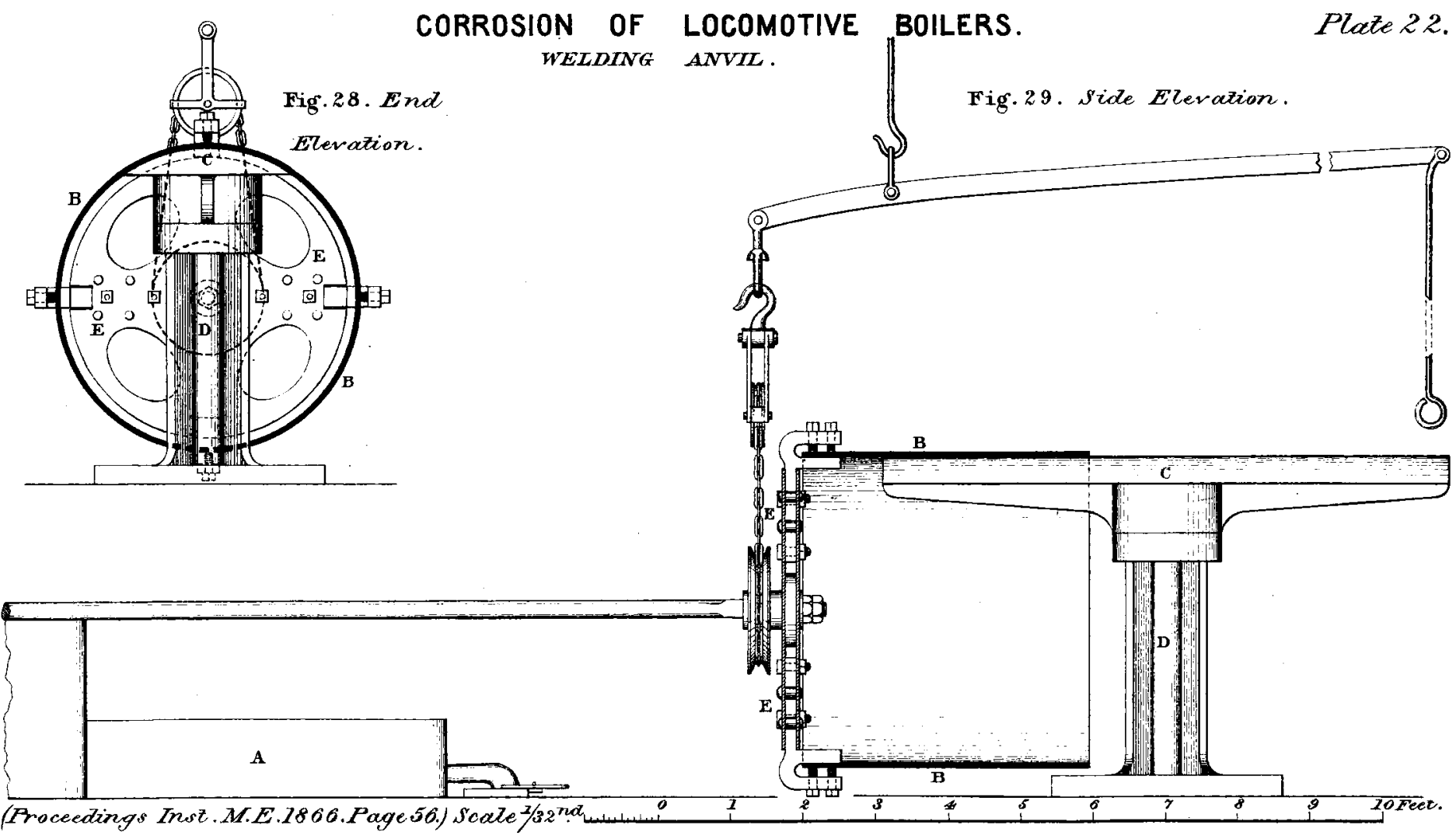


CORROSION OF LOCOMOTIVE BOILERS. Plate 23. BLOCKLNG FURNACE.

(a) Fig. 30. Vertical Section.
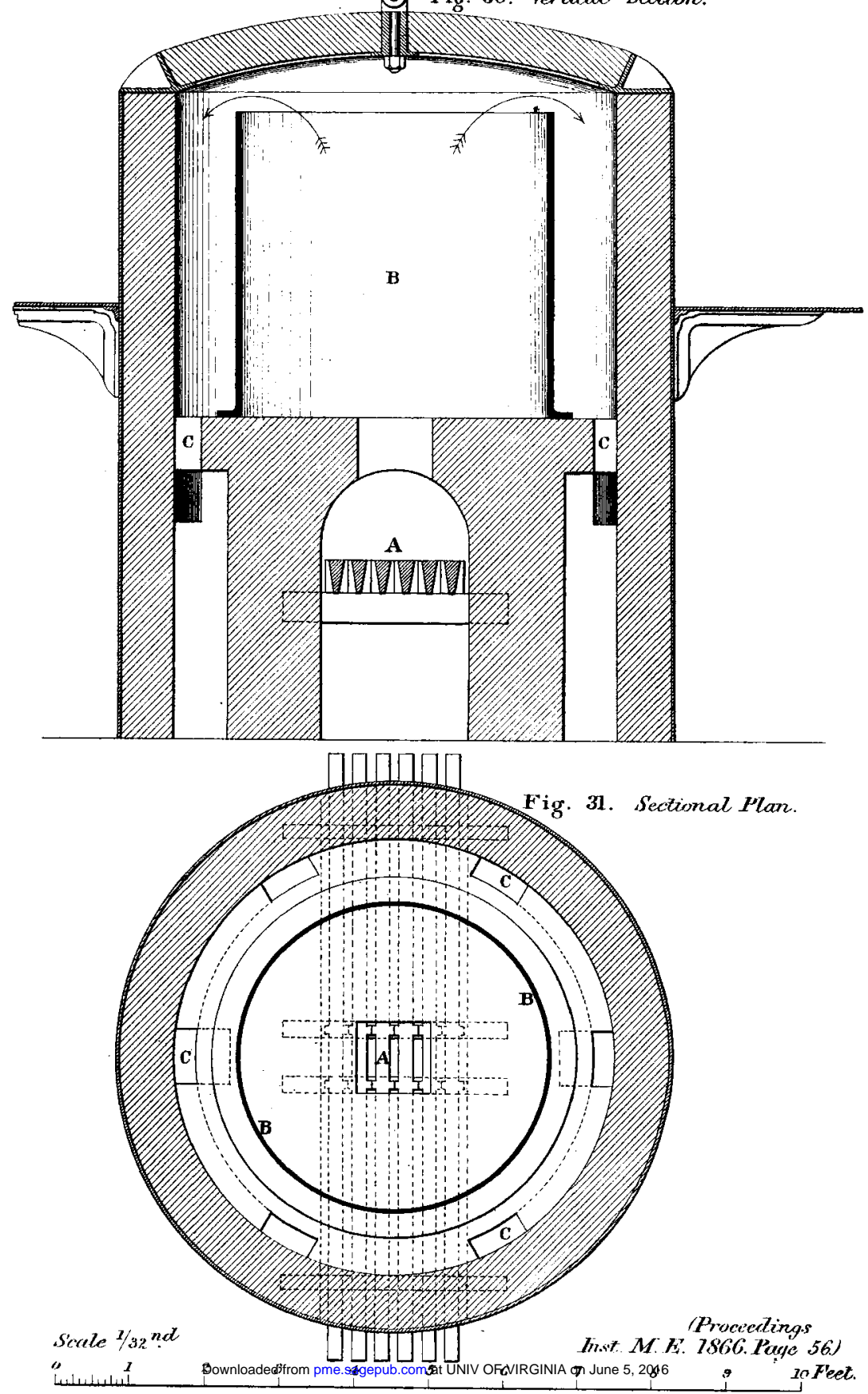
CORROSION OF LOCOMOTIVE BOILERS. Plaze 24. BL OCKTING PRESS.

Fig.32.Vertical section.
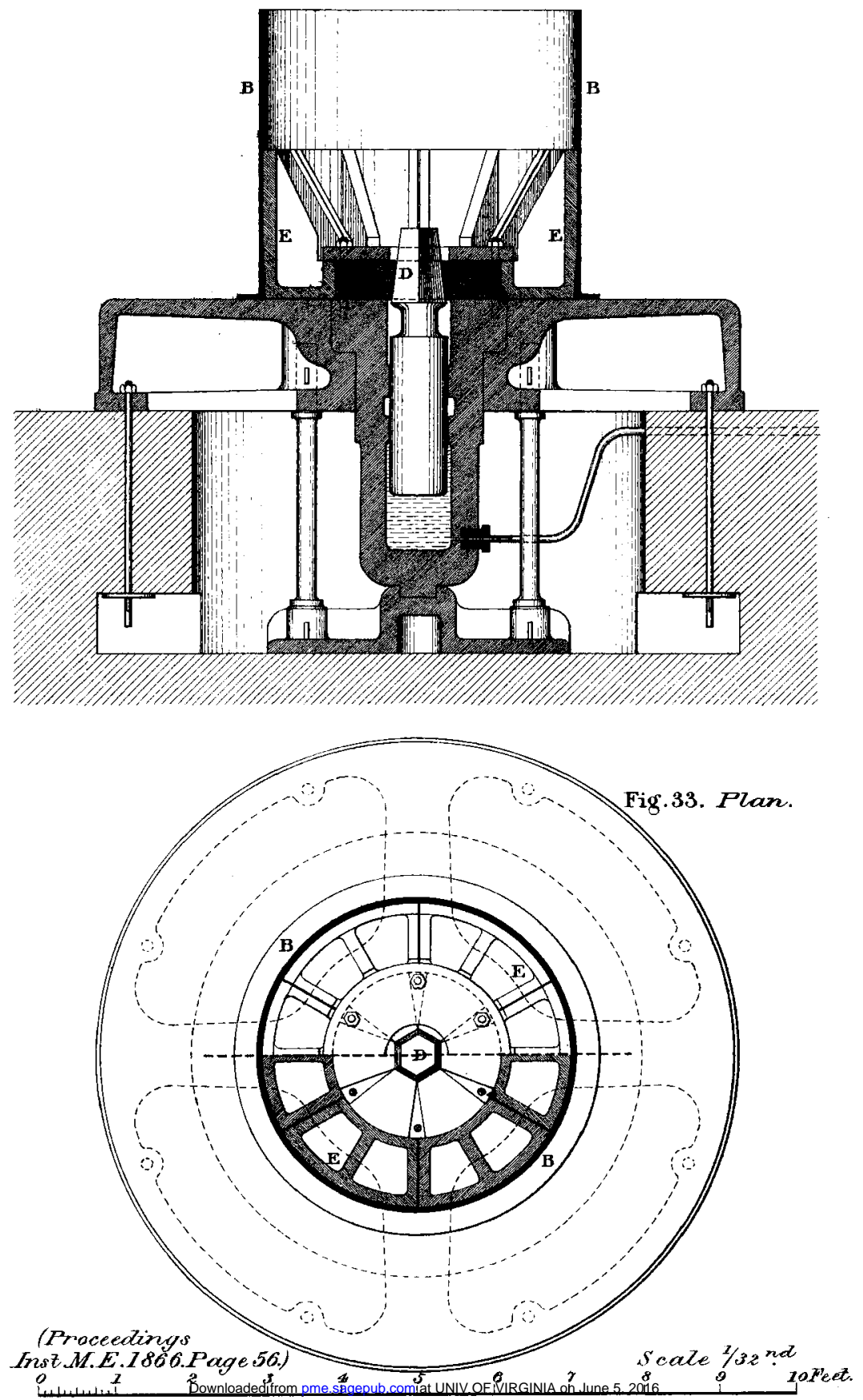